\title{
I 5 The Effects of Disaster on the Mental Health of Individuals with Disabilities
}

\author{
LAURA M. STOUGH
}

\section{I5.I. INTRODUCTION}

Hemingway and Priestley (2006) report that "specific vulnerabilities arise at the intersections of disability, class, gender, and ethnicity" and conclude that people with disabilities "are disproportionately vulnerable to natural hazards primarily as a consequence of social disadvantage, poverty, and structural exclusion" (p. 54). However, while a limited number of studies have examined the physical and social impacts of disaster on individuals with disabilities, the extent to which disasters affect the mental health of individuals with disabilities is rarely addressed. In this chapter, I review results from studies that have systematically studied the effects of disaster on individuals with disabilities and whose results contribute to our understanding of the psychological impact of disaster on this population.

\section{I5.I.I. Defining Disability}

Individuals with disabilities represent a significant - yet often overlooked - portion of the population, accounting for $19.3 \%$ of the total U.S. population (Bault, 2008). The percent of population considered to have a disability varies geographically; in general, poorer communities and most of the U.S. southern states report higher disability rates. The National Organization on Disability estimated that over $23 \%$ of the population in New Orleans affected by Hurricane Katrina were individuals with a disability (National Organization on Disability, 2005a) and reported that it was "clear that a disproportionate number of [hurricane-related] fatalities were people with disabilities" (National Organization on Disability, 2005b). Statistics released support these observations and suggest that of those deaths directly attributable to Katrina, a disproportionate number were elderly or individuals with preexisting disabilities (Aldrich \& Benson, 2008; Bourque, Siegel, Kano, \& Wood, 2006). Disability is present in significant numbers in both developed and developing countries but is strongly correlated with poverty: Up to $80 \%$ of the world population of individuals with disabilities lives in low-income countries, often in disaster-prone areas of the world (World Health Organization, 2005).

"Disability" is not a consistently defined term; Mashaw and Reno (1996) document over 20 definitions of disability used either for purposes of entitlement to governmental services, income support programs, or statistical analysis. "Disability" is most commonly used to refer to individual functioning that is impaired relative to a normative standard of physical, sensory, or cognitive intellectual functioning. Certain chronic diseases, such as multiple sclerosis, are also considered to be disabling conditions, as are some forms of mental illness, particularly when the individual's ability to perform everyday tasks or to live independently is compromised, as may be the case with schizophrenia or major depression. The International Classification of Functioning, Disability and Health (ICF), created by the World Health Organization (2008) provides perhaps the most ecumenical definition of disability and uses a "biopsychosocial" approach to disability. The ICF classification defines disability "as a dynamic interaction between health conditions (diseases, disorders, injuries, traumas, etc.) and contextual factors" (p. 8). Activity limitations 
and participation restrictions to individual functioning according to the ICF classification can include learning and applying knowledge; general tasks and demands; communication, mobility, self-care, domestic life, interpersonal interactions, and relationships; major life areas; and community, social, and civic life. These domains cut across traditionally held categories of disability.

\section{I5.2. DISASTERS AND VULNERABLE POPULATIONS}

Demographic differences shape the risks that people encounter, how they prepare for disasters, and how people are affected when disasters occur (Mileti, 1999). Most fatalities and physical injuries are among those who have lower incomes, have chronic diseases, are elderly or very young, are ethnic minorities, or who are not a member of the language majority (Jonkman \& Kelman, 2005). Much of the difference in how natural disasters affect these demographic groups is due to the contributing variable of poverty. Individuals living in poverty tend to live in substandard housing and lack transportation that would allow them to evacuate in a timely manner, which places them at risk in most disaster situations. Resources such as health and education also decrease vulnerability, and people with disabilities typically have less access to these types of resources. Other situational variables, such as living uninsured in flood plains or being a renter, also contribute to vulnerability (Morrow, 1999; Phillips \& Morrow, 2007), and individuals with disabilities, given their disparate economic status in most areas of the United States, are more likely to live in housing that is at risk in disaster situations.

In an examination of people at risk for earthquake hazards, Tierney, Petak, and Hahn (1988) pointed out that people with disabilities have situational characteristics that may place them at risk for the effects of earthquake. Several factors that they noted were that individuals with disabilities tended to have lower incomes than their nondisabled peers, to be more likely to live in older buildings and near urban centers, and to experience social distancing associated with their label of "disabled." In their sample, 14\% of people with disabilities lived alone and outside of any type of caregiver institution, suggesting that many would not only need assistance following disaster but would need assistance during evacuation preceding disaster.

Phillips and Morrow (2007) suggest that each additional disabling condition, whether situational, demographic, or material, that affects an individual increases their level of vulnerability to a disaster. Individuals with disabilities are at risk for many of these factors, potentially making them one of the groups most vulnerable to the economic and psychological effects of a disaster. Individuals with disabilities and their families are disproportionately poor and thus more likely to live in areas where housing and rental properties are less expensive, such as flood-prone areas. In addition, disasters can cause disabilities through injury, conflict, or the disruption of health-care services following a disaster (International Federation of Red Cross and Red Crescent Societies, 2007).

Most of the reports on the vulnerability of individuals with disabilities have come from anecdotal, media, and policy reports and most of these same reports have been published in the last three years. Interest within the disability community on the affects of disaster on individuals with disabilities was intensified when the Special Needs Assessment for Katrina Evacuees (SNAKE), commissioned and designed by the National Organization on Disability (2005a), investigated shelters along the Gulf Coast following Katrina and found numerous inequities and barriers that affected a wide range of people with disabilities. Policy makers' attention also was drawn to the particular vulnerabilities of individuals with disabilities following Hurricane Katrina. One of the most horrifying incidences occurred at the Santa Rita nursing facility, where 35 elderly individuals with mobility and health impairments died from drowning as a direct result of the flooding following the hurricane. Hurricane Rita, which followed 3 weeks later, resulted in the death of 23 elderly people being evacuated from a nursing home when 
their improperly maintained bus caught fire. The SNAKE report findings, supplemented by anecdotal reports circulated throughout the disability community, generated interest from researchers in effects of disaster on disability, and the majority of currently published research is a direct by-product of this interest following the storm.

Most reports and articles, however, have focused on the support services needs of individuals with disabilities during and following disaster, rather than upon their psychological needs. Psychologically, nonminorities and households with higher socioeconomic status tend to cope better with the effects of disaster, while female heads-of-households, people of low socioeconomic status, and members of minority groups are at risk for a number of negative psychological and economic outcomes (Gladwin \& Peacock 2002; Norris et al., 2002; Norris, Kaniasty, Conrad, Inman, \& Murphy, 2002; Tobin \& Whiteford, 2002). It is thus important to distinguish between those demographic variables that place individuals at risk for physical harm and those that place people at risk for psychiatric illness. As an example, a number of studies have documented higher adverse physical risk for those who are elderly (e.g., Bourque et al., 2006; Perry \& Lindell, 1997) while studies on psychological outcomes have found the elderly to be psychologically resilient postdisaster (Norris \& Murrell 1988; Norris, Kaniasty, et al., 2002).

In the following sections, research that has focused primarily on the effects of disaster on individuals with disabilities will be summarized and findings that have implications for the mental health of individuals with disabilities will be highlighted. For the purposes of summarization, this discussion is organized around the types of disabling conditions identified by the researchers as the target population in their studies.

\section{I5.3. PEOPLE WITH MOBILITY IMPAIRMENTS}

The Centers for Disease Control and Prevention (2006) estimates that 21.2 million people in the United States have a condition that limits basic physical activities such as walking, climbing stairs, reaching, lifting, or carrying objects. Those with mobility impairments are particularly at risk during disaster as they may be physically unable to escape disasters (National Council on Disability [NCD], 2005). Most evacuation plans presuppose the ability of individuals to run, walk, climb, and use alternate forms of egress to escape from the built environment (Christensen, Blair, \& Holt, 2007; National Council on Disability, 2005). For individuals who have mobility impairments, these plans are often inadequate.

The Nobody Left Behind project at the University of Kansas, led by Glen White, has focused a series of studies on the effects of disaster on individuals with physical disabilities. In the first of their published studies (Fox, White, Rooney, \& Rowland, 2007) 30 emergency managers were surveyed to determine the extent to which their county emergency management plan contained procedures to assist people with mobility impairments during disaster. Also assessed was the level of knowledge of these emergency managers on the needs of individuals with disabilities during disaster response. Only $27 \%$ of the participating county emergency managers reported that they had completed training through the FEMA Emergency Planning and Special Populations course, and only $20 \%$ had specific guidelines in place in their counties on how to assist people with disabilities. Perhaps more shocking, 67\% had no intention of modifying their emergency management guidelines to accommodate the needs of people with mobility impairments. The study did not, however, address psychological factors associated with mobility impairments.

In a second study, Rowland and colleagues (Rowland, White, Fox, \& Rooney, 2007) interviewed a group of 12 emergency services managers and firefighters in Kansas. They found that none of the agencies represented by the participants had policies, guidelines, or practices that were specifically designed to assist people with mobility impairments. All of the participating emergency administrators expressed uncertainty about how to address the needs of people with mobility impairments in the future. Again, none 
mentioned psychological supports that these individuals with disabilities might need.

Rooney and White's (2007) study of consumers with mobility impairments is one of the few that have obtained data directly from individuals with disabilities. A total of 56 people with mobility impairments completed an eight-question, online survey on their experiences following disaster. Survey participants resided in 20 different states and in 47 cities. The largest percentage of disasters experienced by the group were, in order of reported frequency, hurricane, earthquake, flooding, severe storms, fire, bomb threat, blackouts, tornadoes, and power outages. Analysis of the results found three common themes regarding what respondents believed was helpful for survival, including preplanning and preparedness measures, personal networks, and help from first responders during and after the disaster. Six problem areas identified by these respondents included (1) lack of worksite or community evacuation plans, (2) being left behind when people without disabilities were evacuated, (3) inaccessible shelters and options for accessible temporary housing, (4) disaster relief personnel who were unaware of disaster relief options for people with disabilities, (5) inadequate infrastructures, such as power, public transportation systems, and access to potable water, elevators, and air conditions, and (6) difficulties returning to daily routines. Eight key informants (13\%) reported some type of postdisaster emotional trauma including fear, grief, nightmares, and generalized stress. It should be noted, however, that these were self-reports of emotions experienced after these events and not the results of a clinical assessment of the mental health of these participants.

Extending the previously summarized studies, White, Fox, Rooney, and Cahill (2007) conducted a fourth study on gaps in services and barriers for people with disabilities following Hurricane Katrina. The researchers surveyed directors of Centers for Independent Living (CILs), which create programs and supports for individuals with disabilities that live in the community, and again surveyed emergency managers. Findings supported those found previously in that emergency managers were inadequately trained on the needs of people with disabilities during and following disaster. The study also included focus groups with 18 people with uncategorized disabilities, along with nine in-depth interviews. In their analysis of this data, the researchers reported that emotional stress and depression were experienced by all of the participants. In some cases, the participants stated that this stress had an impact on their physical health as well. Diagnosis of psychological status pre- and postdisaster was not performed, nor was mental health one of the primary categories identified in the results. The researchers did report on the concern these individuals had about their social relationships, as well as their appreciation for and reliance on family members as supports during evacuation.

Brodie, Weltzien, Altman, Blendon, and Benson (2006) conducted a survey of 680 people staying in one of two large shelters after Hurricane Katrina. Sixteen percent of the sample responded positively when asked, "Has your doctor ever told you that you have a physical disability?" Although this survey did not focus specifically on the needs of individuals with disabilities, responses pertaining to the reasons why these individuals did not evacuate are of interest. A full $22 \%$ responded that they were "physically unable to leave," while $23 \%$ responded, "I had to care for someone who was physically unable to leave." In all, 12\% of those surveyed named one of these two reasons as their primary reason for not evacuating in advance of the hurricane.

In a similar survey conducted by the Harvard School of Public Health (2007) on over 5,000 adults living in counties along the Gulf coastline, $15 \%$ of respondents reported that either they themselves or a member of their household had a chronic illness or disability that would require assistance in the case of a disaster, yet only 58\% had planned for assistance in the case that they did have to evacuate. Of those individuals who had lived in a community that was damaged by a major hurricane in the last 3 years, $6 \%$ responded that they had experienced problems during and immediately following the disaster because they were disabled or chronically ill. An additional 
$8 \%$ responded that they had problems caring for a disabled, chronically ill, or elderly member of their household. The survey did not ask about the mental health of the respondents.

Research on the elderly is addressed in another chapter of this volume; however, the needs of people who are elderly often appear to intersect with those of individuals with disabilities. McGuire and colleagues (2007) surveyed 529 adults over age 65 in southern Louisiana and asked, "Are you limited in any way in any activities because of physical, mental, or emotional problems?" They found that nearly one-third (31.6\%) met the criteria for having some type of disability and that $16.6 \%$ of the total sample reported using an assistance device such as a cane, wheelchair, special bed, or telephone. The authors emphasized that in disaster situations, individuals with disabilities need additional assistance preparing for an evacuation and during an evacuation but did not detail particular psychological or cognitive supports needed by this population.

None of these studies was designed to examine the mental health aspects of disaster; their reports of psychological factors were coincidental, rather than central, in their results. When individuals experience additional barriers following disaster it seems logical to assume that these hardships would negatively affect their mental health; however, none of these studies presented evidence that details the extent or type of psychological consequences experienced by the participants in these studies.

\section{I5.4. PEOPLE WITH SENSORY DISABILITIES}

Individuals with sensory disabilities include those who are visually impaired or blind, representing approximately $3 \%$ of the U.S. population (American Foundation for the Blind, 2008), aand those who are auditorally impaired or deaf, representing approximately $2.4 \%$ of the U.S. population (Galludet Research Institute, 2004). Few published articles exist on the experience of individuals with sensory impairments during and following disaster; however, Barbara
White (2006) provides an autobiographical narrative of her experiences as both a member of the Deaf community and as a researcher. She details her experiences in a shelter in Houston, where she was assisting individuals with hearing impairments, then as an evacuee from a shelter, in anticipation of Hurricane Rita. White emphasizes the inequitable access to communication experienced by the deaf community announcements about the coming hurricanes were only available on selected television stations, translators were not available in shelters, information from FEMA or Red Cross was not communicated in sign language or in another accessible manner. However, while White related the emotional stress and confusion of members of the deaf community in shelters in Houston, she did not focus on the mental health needs of this population following disaster.

The SNAKE Report from the National Organization on Disability (NOD) (2005a) identified the Deaf or hard of hearing population as being the most underserved group in shelters following Hurricane Katrina. The report noted that

Less than $30 \%$ of the shelters had access to American Sign Language interpreters, 80\% did not have TTYs, and $60 \%$ did not have TVs with caption capability. Only $56 \%$ of shelters had areas where oral announcement were posted so people who are deaf, hard of hearing or out of hearing range could go to a specified area to get or read the content of announcements. This meant that the deaf or hard of hearing had no access to the vital flow of information. (pp. 8-9)

The SNAKE report also stated that some individuals with visual disabilities were separated from their assistance dogs or durable medical equipment (e.g., canes) during evacuation but did not provide a count of these cases. The SNAKE Report noted that mental health services were not consistently available across shelters but did not report systematically on the psychological needs of individuals with disabilities in these shelters.

Barile, Fichten, Ferraro, and Judd (2006) compared the experiences of individuals with 
disabilities to those of their nondisabled peers during and following the 1998 ice storm in Canada. In their study, two individuals reported a hearing impairment, and six reported having a visual impairment. The researchers asked participants, "Compared to most others, how do you feel you coped psychologically during the ice storm period?" and "Compared to most others, how do you feel you coped physically during the ice storm period?" Participants with and without disabilities had similar ratings on their experiences during the ice storm; in fact, while participants with disabilities had physically fared somewhat worse than their counterparts without disabilities they reported psychologically coping slightly better. The researchers also asked participants to report on symptoms of anxiety or depression experienced during the ice storm but found no difference between participants with and without disabilities. They also found no differences in self-reported feelings of anxiety and depression before the storm as when compared to feelings after the storm. The authors suggested that individuals with disabilities are accustomed to encountering barriers in their lives and that these experiences may provide them with psychological resilience to the impacts of disaster.

\section{I5.5. PEOPLE WITH COGNITIVE DISABILITIES}

Individuals with cognitive disabilities include those individuals who are labeled as having autism, developmental disabilities, traumatic brain injury, learning disabilities, or intellectual disabilities (formally referred to as mental retardation). Depending on the definition, $15 \%$ to $20 \%$ of the population can be said to have some type of cognitive disability, with the largest category being a specific learning disability.

Christ and Christ (2006) reported on the academic and behavior reactions of four children with learning disabilities whose firefighter fathers had died in the September 11, 2001, World Trade Center attack in New York City. They compared the reactions of these children to their same aged peers and found that the two groups exhibited somewhat different reactions.
Following an initial grief reaction, most of the children with disabilities seemed to "tune out the painful reminders and focus on less painful topics more rapidly than their siblings or other children whose father was killed" (p. 71). The researchers concluded that a strong protective factor was support from their special education teachers and related school supports. In addition, the children in the study experienced a change in status at their school as a child who had lost a father who was a hero, rather than their previous primary status as a child with a disability.

In addition to this published work, several conference papers have reported on the experiences of individuals with intellectual disabilities. Joseph Scotti, Stevens, Cavender, Morford and his colleagues at Western Virginia University (2007) have studied the responses to emergency events by 405 individuals with intellectual disabilities and related developmental disabilities. Over $30 \%$ of the caretakers of these individuals reported that they became distressed during emergency situations and had stressed responses to emergency related stimuli, including sirens/ bells (37\%), fire drills (22\%), flashing lights (22\%), strangers (18\%), and emergency personnel (10\%). These findings suggested that cues used to signal looming disasters may actually trigger stress reactions in individuals with cognitive disabilities, rather than assist them in appropriately preparing for evacuation or sheltering. Most family members similarly reported that these individuals displayed notable emotional reactions to these events, including fear, helplessness, and horror. Interestingly, the number of traumatic events reported was positively correlated with the number of medical and behavioral problems as well as the severity of the medical problems that had been reported by the family member. Distress ratings were negatively correlated with the age of the individual, their level of independence, the extent to which they responded positively to strangers, and their level of independence following instructions from strangers.

A second study by Scotti, Stevens, Cavender, Jacoby and colleagues (2007) analyzing the same database examined the prevalence and impact of 
traumatic events, including disasters. Primary caretakers of individuals with intellectual disabilities reported that their wards had experienced an average of two to three types of potentially traumatic events over their lifetime. Reactions to traumatic events included reexperiencing, hyperarousal, avoidance, and changes in sleep patterns. The researchers concluded that persons with mental retardation and developmental disabilities appear to exhibit symptoms and distress that resemble posttraumatic stress disorder (PTSD) when exposed to traumatic events, but they noted that the clinical differentiation of PTSD from behavioral problems in this population would be challenging.

Stough and Sharp (2007) conducted a study of the long-term recovery of 31 individuals with disabilities who had been directly affected by Hurricane Katrina. Individuals with disabilities or their family members participated in one of five focus groups that were conducted in the Gulf States. Seven of the participants or their family members had a cognitive disability, while over half (a total of 16) reported having more than one disability. Participants overwhelmingly identified family members and friends as their primary sources of support following the disaster. In response to the question "What has prevented your recovery from Hurricane Katrina?" not one of the participants believed that they and their family had "recovered," although the focus groups took place nearly two years following the disaster. In addition, almost all of the participants made a negative statement about their current level of depression or stress, even though the prompt was not designed to elicit this information. Over half of the participants believed that these self-identified feelings of depression or despair had negatively affected their ability to search for services, obtain employment, and to recover from the disaster.

\section{I5.6. PSYCHIATRIC DISABILITIES}

Mental illness is not considered disabling in most instances, and while adverse situational variables certainly may contribute to psychological distress following disaster, they do not necessarily lead to psychiatric illness. In keeping with the World Health Organization's definition, the Americans with Disabilities Act considers a mental illness disabling only if it "substantially limits one or more of the major life activities" (U.S. Equal Employment Opportunity Commission, 1990). According to American Psychiatric Association (APA) (2000), a disorder must interfere markedly with social, occupational, or school functioning to be considered a severe mental illness. Diagnoses included under the category of severe mental illness generally include schizophrenia or its related psychotic disorders, bipolar affective disorder, autism, major depression, obsessivecompulsive disorder (OCD), and panic disorder (Reggeri, Leese, Thornicroft, Bisoffi, \& Tansella, 2000). It is estimated that $2.8 \%$ of the population has a severe mental illness (Narrow et al., 2000). PTSD is the most frequent diagnosis assessed by researchers following disaster exposure but is not, when presented on its own, usually considered a severe mental illness.

Bromet, Schulber, and Dunn (1982), in an early study on disaster and individuals with severe mental illness, assessed a group of 151 outpatients with psychiatric illnesses living near the Three Mile Island nuclear facility during the 1979 disaster. The group's postdisaster mental health status was compared with a group of similarly diagnosed individuals living near a nonaffected nuclear plant. The researchers assessed the two groups for stress, depression, and anxiety at three different time points following the Three Mile Island disaster. While they found increased levels of anxiety or depressive episodes in both groups following the disaster, they found no difference between the two groups on these measures.

Three studies have examined institutionalized populations with severe mental illness exposed to disasters, which allowed for verification of clinical diagnosis both pre and postdisaster. In the first study, Godleski, Luke, DiPreta, Kline, and Carlton (1994) reported on a group of 22 patients at a chronic rehabilitation unit that experienced a direct impact from Hurricane Iniki. The clinical status of the patients was assessed at three time periods during the storm, beginning 1 week after 
the storm and up to 12 months afterward. The researchers reported that following the disaster none of the patients met the criteria for PTSD, none required an increase in medications, and there was no additional decompensation of the mental health status of the patients. The second study, by Stout and Knight (1990), was conducted on 15 adolescents receiving inpatient treatment in a facility that was flooded. The adolescents were found to use positive coping mechanisms following the disaster, and the researchers noted no increase in psychopathology. A third study by Bystritsky, Vapnik, Maidment, Pynoos, and Steinberg (2000) examined the reaction of two groups of patients with anxiety disorders, one with OCD and the other with panic disorders, who were directly impacted by the Northridge earthquakes of 1994. Neither groups displayed an increase in their primary symptomatology following the disaster. Interestingly, measures of anxiety and depression significantly increased in the group with panic disorders but not in the group with OCD. It should be noted that the group with OCD was participating in a partial hospitalization program while the patients with panic disorder were participating in studies on panic disorder. Together, these three studies suggest that individuals with severe mental illness may be buffered from additional psychological impacts of disasters when they receive ongoing psychiatric care in a therapeutic environment.

Results from two other studies similarly suggest (although they did not statistically analyze the level of psychiatric functioning pre- and postdisaster) that intensive community treatment programs may prevent additional pathology in individuals with severe mental illness (Lachance, Santos, \& Burns, 1994; McMurray \& Steiner, 2000). The constant across these studies was continuity of mental health supports following disaster. Again, it may be that when ongoing psychological supports are available to individuals with severe mental illness, psychological deterioration is mitigated.

In contrast to these findings, Chubb and Bisson (1996) found that the majority (50\%) of institutionalized victims, who were involved in a deadly vehicle collision, met criteria for PTSD following the accident. A higher level of morbidity was found in those with depression and anxiety postdisaster, but following the disaster victims with schizophrenia actually had lower scores on measures of depression, anxiety, and PTSD.. In contrast results reported in the Bromet et al. (1982), and Bystritsky et al. (2000), and Godleski et al. (1994) studies, the victims in this study directly witnessed the deaths of family members and caretakers during the event, which may have affected the level of PTSD experienced by these participants.

Several other studies have examined populations with severe mental illness receiving institutionalized or outpatient psychiatric care following the attacks of September 11th (see DeLisi, Cohen, \& Maurizio, 2004; Franklin, Young, \& Zimmerman, 2002; Riemann, Braun, Greer, \& Ullman, 2004; Taylor \& Jenkins, 2004). However, the patients in these studies were not at physical risk during these disasters, were not directly impacted by the event, and were at substantial distance from any of the sites where the attacks occurred. In the study by DeLisi and colleagues, patients were institutionalized at Bellevue Hospital and had the opportunity to view the event distantly from windows at the hospital, which was three miles away from the Towers, but were not questioned if they actually had seen the event occur. However, no significant difference in increase in morbidity or occurrence of new symptoms was found between those patients who did and who did not have the opportunity to view the destruction. Person and Fuller (2007) give a more extensive review of this set of studies, as well as a detailed discussion of the psychological measures used in these and in several other studies.

Another group of studies have analyzed the results of disaster on large populations that included participants both with and without diagnosed mental health disorders. Robins, Fischback, Smith, Cottler, Solmon, and Goldring (1986) interviewed 252 individuals affected by the multiple Times Beach disasters of flooding, radiation, tornados, and dioxin and matched them to a sample that had not been exposed. They found little evidence that these disasters 
had significant effects on mental health other than an increase in PTSD associated with the event. In addition, they found little evidence that these disasters caused the recurrence of mental illness or caused new mental illnesses. They concluded that most individuals, regardless of preexisting mental health status, are psychological resilient in the face of disaster.

Several studies have examined the association between severe mental illnesses and PTSD that has been diagnosed in relationship to disasters. Breslau, Davis, Andreski, and Peterson (1991) hypothesized that PTSD may lead to other psychiatric disorders, rather than the converse argument that prior disorders lead to PTSD vulnerability. McMillen, North, Mosley, and Smith (2002) empirically examined explanations for the high rates of psychiatric comorbidity that are typically associated with PTSD. They examined a sample of 162 survivors of the Great Midwest Floods using the Diagnostic Interview Schedule (DIS) and its Disaster Supplement. Thirty-five of their subjects met criteria for PTSD related to the flood, and the diagnosis of PTSD was frequently comorbid with other disorders. Although 10\% of the sample developed a new, non-PTSD psychiatric disorder after the flood, these disorders were rare in the absence of PTSD symptoms. The results supported a model in which PTSD contributed to the development of other disorders following trauma but found no support for the hypothesis that other psychological disorders develop independently of PTSD following disaster.

In another study on the effects of the Midwest floods, North, Kawaskai, Spitznagel, and Hong (2004) examined a sample of 162 individuals, $44 \%$ of who had a predisaster psychiatric illness at sometime in their life. Only $25 \%$ of the sample reported any new somatoform symptom after the flood event, and for two-thirds of these individuals, the new illness was flood-related PTSD; flood-related PTSD developed three times as often in people with a preexisting psychiatric disorder. New somatization disorders and new alcohol or substance abuse were not observed results of the floods. Some participants did develop new somatoform symptoms (though not pathology), but these symptoms were associated with the presence of preflood psychiatric disorders. These large-scale studies suggest that the presence of postdisaster psychiatric illness is highly dependent on predisaster levels of illness and support other studies that have found that the majority of victims do not develop PTSD following disaster.

Individuals with preexisting psychiatric disorders may be at additional risk due to events that occur postdisaster. The National Council on Disability (2005) released a report following hurricanes Katrina and Rita that identifies a number of mental health concerns for people with psychiatric disabilities following disaster. One of these most basic identified needs was access to psychotropic medicines following the disaster as most individuals who evacuated did so without their medications or with only a limited supply. Shelters used in these two disasters were reported to lack psychiatric support, and hurricane victims therefore experienced disruption in their therapeutic treatment. NCD also reported inappropriate institutionalization of people with psychiatric disabilities postdisaster, and noted that institutionalization could have been avoided simply by refilling needed psychiatric medications.

In summary, studies on individuals with preexisting psychiatric illness suggest that continuity of psychological and other supports may mitigate the effects of disaster, that higher rates of PTSD occur in these individuals than in those without preexisting disorders following disaster, but that the development of new psychiatric disorders unrelated to PTDS symptomology is rare in most instances.

\subsection{SUMMARY OF RESEARCH ON INDIVIDUALS WITH PREEXISTING DISABILITIES}

The limited empirical research on the effects of disaster on individuals with disabilities, with the exception of the literature on preexisting mental health issues, focuses on physical or service barriers experienced during and following disaster rather than on the psychological impacts 
experienced by these individuals. The literature suggests that people with disabilities, including those with severe mental illness, have unequal access to information about impending disaster, are treated differently during the relief stage of disaster, and encounter additional barriers in recovering from disaster. Much less clear are the psychological effects of disaster on individuals with disabilities. Excluding the small collection of empirical studies on individuals with preexisting psychiatric illnesses, researchers have virtually ignored the psychological effects of disaster on individuals with intellectual disabilities, physical disabilities, or sensory impairments. In part, the lack of attention given to the mental health needs of individuals with nonpsychiatric disabilities can be attributed to the theoretical orientation of the researchers who have conducted this research: Most are researchers from the disability field rather than psychologists or psychiatrists. Thus, studies that do focus on the effects of disaster on people with disabilities tend to have a policy or social support focus rather than upon the mental health of this population. In addition, researchers have generally given limited attention to the mental health of individuals with disabilities, with the exception of a collection of studies on depression in individuals with mental retardation (e.g., Esbensen \& Benson 2006; Lunsky, 2004), and this same lack of attention can be noted in the disaster-related literature.

\section{I5.8. FUTURE RESEARCH}

Two lines of research seem to be the most promising in examining the effects of disaster on people with disabilities. First is the question of whether the mental health of people with disabilities is disproportionately affected by disaster. Reliable measures of individual psychological functioning both before and after a disaster event will be needed to measure impact, as well as a comparison with individuals without disabilities. As it can be difficult to obtain reliable and valid measures of psychological functioning on many individuals with disabilities, researchers will be challenged to assess if disasters differentially affect the mental health status of people with disability or if psychological consequences are manifested differently than those in the nondisabled population.

The second line of research is on the psychosocial consequences of disaster for people with disabilities. The social and personal supports that surround individuals with disabilities are fragile and appear to be particularly susceptible to the type of disruption that disasters incur. Several studies have suggested that victims of disaster choose family and friends as their most frequent method for coping with disaster (Haines, Hurlbert, \& Beggs, 1999). However, the extent to which these support systems are disrupted following disaster and whether these systems are more difficult for people with disabilities to reassemble has not been systematically examined.

We know that individuals with disabilities tend to have lower income, fewer people in their social networks, and lower rates of education - all of which are factors that place other vulnerable groups at physical risk following disaster (Bourque et al., 2006). The question for researchers, then, is if the loss of these supports places people at additional risk for psychological disorders following disasters. Theories that suggest that the loss of resources and psychosocial supports following disaster affect psychological hardiness, for example, Hobfall's (1989) theory of conservation of resources or Kaniasty and Norris' (1993) social support deterioration model, would be of most use in framing this line of research. However, the loss of supports available to individuals with disabilities may tell us more about how disaster exacerbates existing social inequalities than it does about the mental health effects of disaster on this population.

\section{REFERENCES}

Aldrich, N., \& Benson, W.F. (2008). Disaster preparedness and the chronic disease needs of vulnerable older adults. Preventing Chronic Disease, 5(1), A27.

American Foundation for the Blind (2008). Facts and figures on Americans with vision loss. (September, 2008); http://www.afb.org/Section.asp?SectionI $\mathrm{D}=15$ \&DocumentID $=4398$ 
American Psychiatric Association. (2000). Diagnostical and statistical manual of mental disorders 4 th ed., Text Revision. Washington, DC: American Psychiatric Association.

Barile, M., Fitchten, C., Ferraro, V., \& Judd, D. (2006). Ice storm experiences of persons with disabilities: Knowledge is safety. The Review of Disability Studies I, 2(3), 35-48.

Bault, M. (2008). Disability status and the characteristics of people in group quarters: a brief analysis of disability prevalence among the civilian noninstitutionalized and total populations in the American Community Survey. United States Census Bureau Report. (February 2008); http://www.census.gov/ hhes/www/disability/GQdisability.pdf

Bourque, L. B., Siegel, J. M., Kano, M., \& Wood, M. M. (2006). Weathering the storm: The impact of hurricanes on physical and mental health. The Annals of the American Academy, 604, 129-151

Breslau, N., Davis, C. G., Andreski, P., \& Peterson, E. L. (1991). Traumatic events and posttraumatic stress disorder in an urban population of young adults. Archives of General Psychiatry, 48, 216-222.

Brodie, M., Weltzien, E, Altman, D., Blendon, R. J., \& Benson, J.M. (2006). Experiences of Hurricane Katrina evacuees in Houston shelters: Implications for future planning. American Journal of Public Health, 96(8), 1402-1408.

Bromet, E., Schulberg, H.C., \& Dunn, I. (1982). Reactions of psychiatric patients to the Three Mile Island nuclear accident. Archives of General Psychiatry, 39(6), 725-730.

Bystritsky, M.D., Vapnik, R., Maidment, K., Pynoos, R.S., \& Steinberg, A. M. (2000). Acute responses of anxiety disorder patients after a natural disaster. Depression and Anxiety, 11, 43-44.

Centers for Disease Control. (2006). Disability. (February 2008); http://www.cdc.gov/omhd/Populations/ Disability/Disability.htm.

Christ G.H., \& Christ, T.W. (2006). Academic and behavioral reactions of children with disabilities to the loss of a firefighter father: The New York World Trade Center attack 9/11/01. The Review of Disability Studies, 2(3), 68-77.

Christensen, K. M., Blair, M.E., \& Holt, J.M. (2007). The built environment, evacuations, and individuals with disabilities: A guiding framework for disaster policy and preparation. Journal of Disability Policy Studies, 17(4), 249-253.

Chubb, H.L., \& Bisson, J.I. (1996). Early psychological reactions in a group of individuals with preexisting and enduring mental health difficulties following a major coach accident. The British Journal of Psychiatry, 169(4), 430-433.

DeLisi, L.E., Cohen, T.H., \& Maurizio, A.M. (2004). Hospitalized psychiatric patients view the World
Trade Center disaster. Psychiatry Research, 129(2), 201-207.

Esbensen, A. J., \& Benson, B.A. (2006). Diathesisstress and depressed mood. American Journal on Mental Retardation, 111(2), 100-112.

Fox M.H., White, G. W. Rooney, C., \& Rowland, R. L. (2007). Disaster preparedness and response for persons with mobility impairments: Results from the University of Kansas Nobody Left Behind Study. Journal of Disability Policy Studies, 17(4), 196-205.

Franklin, C. L., Young, D., \& Zimmerman, M. (2002). Psychiatric patients' vulnerability in the wake of the September 11th terrorist attacks. The Journal of Nervous and Mental Disease, 190(12), 833-838.

Galludet Research Institute. (2004). A brief summary of estimates for the size of the deaf population in the USA based on available federal data and published research. (February 2008); http://gri. gallaudet.edu/Demographics/deaf-US.php

Gladwin, H., \& Peacock, W.G. (2000). Warning and evacuation: A night for hard houses. In W. Peacock, B. Morrow, \& H. Gladwin (Eds.), Hurricane Andrew: Ethnicity, gender and the sociology of disasters. Miami: International Hurricane Center.

Godleski, L.S., Luke, K. N., DiPreta, J.E., Kline, A. E., \& Carlton, B.S. (1994). Responses of state hospital patients of Hurricane Iniki. Hospital and Community Psychiatry, 45(9), 931-933.

Haines, B. A., Hurlbert, J. S., \& Beggs, J. J. (1999). The disaster framing of the stress process: A test of an expanded model. International Journal of Mass Emergencies and Disasters, 17(3), 367-397.

Harvard School of Public Health. (2007). Hurricane readiness in high-risk areas. (January 2008); http:// www.hsph.harvard.edu/news/pressreleases/files/ Hurricane_2007_Survey_state_results.doc

Hemingway, L., \& Priestley, M. (2006). Natural hazards, human vulnerability and disabling societies: A disaster for disabled people? The Review of Disability Studies: An International Journal, 2(3), 57-67.

Hobfall, S.E. (1989). Conservation of resources: A new attempt at conceptualizing stress. American Psychologist, 44, 513-524.

International Federation of Red Cross and Red Crescent Societies. (2007). World disasters report: Focus on discrimination. Satigny/Verner, Switzerland: ATAR Roto Presse.

Jonkman S.N., \& Kelman, I. (2005). An analysis of the causes and circumstances of disaster deaths. Disasters, 29(1), 75-97.

Kaniasty, K., \& Norris, F. H. (1993). A test of the social support deterioration model in the context of 
natural disaster. Journal of Personality and Social Psychology, 64, 395-408.

Lachance, K. R., Santos, A. B., \& Burns, B. J. (1994) The response of an assertive community treatment program following a natural disaster. Community Mental Health Journal, 30(5), 505-515.

Lunsky, Y. (2004). Suicidality in a clinical and community sample of adults with mental retardation. Research In Developmental Disabilities, 25(3), 231-243.

Martz, E., \& Cook, D. W. (2001). Physical impairments as risk factors for the development of posttraumatic stress disorder. Rehabilitation Counseling Bulletin, 44(4), 217-221.

Mashaw, J., \& Reno, V. (1996). Balancing security and opportunity: The challenge of disability income policy. Report of the Disability Policy Panel. Washington, DC: National Academy of Social Insurance.

McGuire, L.C., Ford E.S., \& Okoro, C.A. (2007). Natural disaster and older U.S. adults with disabilities: Implication for evacuation. Disasters, 31(1), 49-56.

McMillen, C., North, C., Mosley, M., \& Smith, E. (2002). Untangling the psychiatric comorbidity of postraumatic stress disorder in a sample of flood survivors. Comprehensive Psychiatry, 43(6), 478-485

McMurray, L., \& Steiner, W. (2000). Natural disaster and service delivery to individuals with severe mental illness- Ice storm 1998. Canadian Journal of Psychiatry, 45(4), 383-385.

Mileti, D.S. (1999). Disasters by design: A reassessment of natural hazards in the United States. Washington, DC: John Henry Press.

Morrow, B.H. (1999). Identifying and mapping community vulnerability. Disasters, 23(1), 1-18.

Narrow, W.E., Regier, D.A., Norquist, G., Rae, D.S., Kennedy, C., \& Arons, B. (2000). Mental health service use by Americans with severe mental illnesses. Social Psychiatry and Psychiatric Epidemiology, 35(4), 147-155.

National Council on Disability. (2005). Saving lives: Including people with disabilities in emergency planning. (February 2008); http://www.ncd.gov/ newsroom/publications/2005/saving_lives.htm.

National Organization on Disability. (2005a). Report on special needs assessment for Karina evacuees (SNAKE) Project. Washington, DC (October 2005); http://www.nod.org/Resources/PDF/katrina_ snake_report.pdf.

(2005b). The Impact of Hurricanes Katrina and Rita on people with disabilities: A look back and remaining challenges. (September 2007); http:// www.ncd.gov/newsroom/publications/2006/ hurricanes_impact.htm
Norris, F.H., Friedman, M. J., Watson, P.J., Byrne, C.M., Diaz, E., \& Kaniasty, K. (2002). 60,000 Disaster Victims Speak: Part I. An empirical review of the empirical literature, 1981-2001. Psychiatry, 65(3), 207-239.

Norris, F.H., Kaniasty K., Conrad, M., Inman G., \& Murphy A. (2002). Placing age differences in cultural context: A comparison of the effects of age on PTSD after disasters in the U.S., Mexico, and Poland. Journal of Clinical Geropsychiatry, 8 , 153-173.

Norris, F, \& Murrell, S. (1988). Prior experience as a moderator of disaster impact on anxiety symptoms in older adults. American Journal of Community Psychology, 16, 665-683.

North, C.S., Kawaskai, A., Spitznagel, E. L., \& Hong, B. A. (2004). The course of PTSD, major depression, substance abuse, and somatization after a natural disaster. The Journal of Nervous and Mental Disease, 192(12), 823-829.

Perry, R.W., \& Lindell, M.K. (1997). Aged citizens in the warning phase of disasters. International Journal of Aging and Human Development, 44, 257-267.

Person, C., \& Fuller, E. J. (2007). Disaster care for persons with psychiatric disabilities: Recommendations for policy change. Journal of Disability Policy Studies, 17(4), 238-248.

Phillips, B. D., \& Morrow, B. H. (2007). Social science research needs: Focus on vulnerable populations, forecasting, and warnings. Natural Hazards Review, 8(3), 61-68.

Riemann, B.C., Braun, M.M., Greer, A., \& Ullman, J. M. (2004). Effects of September 11 on patients with obsessive compulsive disorder. Cognitive Behavior Therapy, 33(2), 60-67.

Reggeri, M., Leese, M., Thornicroft, G., Bisoffi, G., \& Tansella, M. (2000). Definition and prevalence of severe and persistent mental illness. The British Journal of Psychiatry, 177, 149-155

Robins, L.N., Fischback, R.L., Smith, E.M., Cottler, L. B., Solomon, S.D., \& Goldring, E. (1986). Impact of disaster on previously assessed mental health. In J.H. Shore (Ed.), Disaster stress studies: New methods and findings. Washington, DC: American Psychiatric Press, Inc.

Rooney, C., \& White, G. W. (2007). Narrative analysis of a disaster preparedness and emergency response survey from persons with mobility impairments. Journal of Disability Policy Studies, 17(4), 206-215.

Rowland, J.L., White, G. W., Fox, M.H., \& Rooney, C. (2007). Emergency response training practices for people with disabilities. Journal of Disability Policy Studies, 17(4), 216-222. 
Scotti, J.R., Stevens S., Cavender, A, Morford, M., Jacoby V., Freed, R., et al. (). Response of persons with mental retardation/developmental disabilities to emergency situation: Implications for disaster preparedness. Presented at the annual meeting of the International Society for Traumatic Stress Studies, Baltimore, MD.

Scotti, J.R., Stevens S., Cavender, A., Jacoby, V., Kalvitis, J., Morford, A., et al. (2007). Trauma in persons with mental retardation/developmental disabilities: Relation between trauma history, behavior problems, and functional level. Presented at the annual meeting of the International Society for Traumatic Stress Studies, Baltimore, MD.

Stout, C.E., \& Knight, T. (1990). Impact of a natural disaster on a psychiatric inpatient population: Clinical observations. The Psychiatric Hospital, 21(3), 129-135.

Stough, L. M., \& Sharp, A. N. (2007). The recovery of individuals with disabilities following Hurricane Katrina. Presented at the annual meeting of the International Society for Traumatic Stress Studies, Baltimore, MD.

Taylor, M., \& Jenkins, K. (2004). The psychological impact of September 11 terrorism on Australian inpatients. Australiasian Psychiatry Bulletin of the Royal Australian and New Zealand College of Psychiatrists, 12(3), 253-255.
Tierney, K. J., Petak, W. J., \& Hahn, H. (1988). Disabled persons \& earthquake hazards. Boulder, CO: Institute for Social and Behavioral Science, Natural Hazards Research and Applications Information Center.

Tobin, G. A., \& Whiteford, L. M. (2002). Community resilience and volcano hazard: the eruption of Tungurahua and evacuation of the faldas in Ecuador. Disasters, 26(1), 28-48.

United States Equal Opportunities Commission. The Americans with Disability Act. (February 2008); http://www.eeoc.gov/types/ada.html

White, B. (2006). Disaster relief for deaf persons: Lessons from Hurricanes Katrina and Rita. The Review of Disability Studies, 2(3), 49-56.

White, G.W., Fox, M.H., Rooney, C., \& Cahill, A. (2007). Assessing the impact of Hurricane Katrina on persons with disabilities. Lawrence, KS: The University of Kansas, The Research and Training Center on Independent Living.

World Health Organization. (2005). Disability, including prevention, management and rehabilitation. (February 2008); http://www.who.int/gb/ebwha/ pdf_files/WHA58/A58_17-en.pdf

(2008). International classification of functioning, disability and health. Introduction. (March 2008); http://www.who.int/classifications/icf/ site/icftemplate.cfm?myurl=homepage.html\& mytitle $=$ Home $\% 20$ Page. 